\title{
Psödobüllöz anetodermik pilomatrikoma
}

\author{
Pseudobullous anetodermic pilomatricoma
}

\section{Sevgi Akarsu, Turna Illknur, Melike Kibar, Özlem Özbağçıvan, Erdener Özer*, Emel Fetil}

Dokuz Eylül Üniversitesi Tıp Fakültesi, Deri ve Zührevi Hastalıkları Anabilim Dalı ve *Patoloji Anabilim Dalı, İzmir, Türkiye

\section{Özet}

Pilomatrikoma (PM) kıl matriksi ve kıl şaftının primitif hücrelerinden köken alan; çoğunlukla baş, boyun ve üst ekstremitelerde görülen asemptomatik, yavaş büyüyen, benin bir deri tümörüdür. Tipik lezyon genellikle soliter, sert kıvaml, üzeri normal veya eritemli deri ile örtülü, büyüklükleri 0,5 ile $3 \mathrm{~cm}$ arasında değişen, derin yerleşimli dermal veya subkutanöz nodül ile karakterizedir. Nadir görülen atipik PM formları içinde yer alan büllöz ve anetodermik PM formlarında lezyonların üzerinde büllöz görüntü oluşabilmektedir. Burada sağ kolunda üzerinde kalın duvarlı gevşek büllöz görünüm izlenen anetodermik PM'lı 11 yaşında bir kız olgu sunulmaktadır. (Türkderm 2013; 47: 114-6)

Anahtar Kelimeler: Adneksiyal tümör, pilomatrikoma, büllöz görünüm, büllöz pilomatrikoma, anetodermik pilomatrikoma

\section{Summary}

Pilomatricoma (PM) is an asymptomatic, slowly growing, benign skin tumour originating from primitive cells of the hair matrix and hair shaft and appears mostly on the head, neck, and the upper extremities. Typical lesion is usually characterized by a solitary, firm, deep-seated dermal or subcutaneous nodule, covered by normal or erythematous skin, and usually varying in size from 0.5 to $3 \mathrm{~cm}$. Bullous appearance can occur on the lesions of bullous PM and anetodermic PM which are located in the rare atypical forms of PM. Here, we present an 11-year-old girl with an anetodermic PM on her right arm that showed thick-walled flaccid bullous formation over it. (Turkderm 2013; 47: 114-6)

Key Words: Adnexal tumor, pilomatricoma, bullous appearance, bullous pilomatricoma, anetodermic pilomatricoma

\section{Giriş}

Pilomatrikoma (PM) genellikle düzgün yüzeyli, sert kıvamlı, mobil fakat deriye yapışık, boyutları 0,5 ile $3 \mathrm{~cm}$ arasında değişen, yavaş büyümeye eğilimli, normal deri renginde ya da pembe-mavi renkli subkutanöz soliter bir kitle şeklinde karşımıza çıkar. Inflamasyon veya ülserasyon yokluğunda çoğunlukla asemptomatik olan lezyonun üzerindeki epidermiste bazen renk değişikliği, atrofi, keratinizasyon veya erozyon gibi bulgular izlenebilmektedir1,2. Sıklıkla baş, boyun ve üst ekstremitelerde yerleşen lezyonlar daha nadir olarak gövde ve alt ekstremitelerde de görülebilmektedir1-5. Çok nadir de olsa malin dönüşüm gösterebilen PM'nın klasik formuna ilaveten multipl, malin, perforan, büllöz ve anetodermik olmak üzere nadir görülen atipik PM formları da tanımlanmıştır6-17. Burada sağ kolundaki PM lezyonu üzerinde kalın duvarlı gevşek psödobüllöz görünüm izlenen ve histopatolojik olarak anetodermik özellikler saptanan 11 yaşında bir kız olgu sunulmaktadır.

\section{Olgu}

Sağ kolundaki sert kabarıklık yakınması ile başvuran 11 yaşındaki kız olgu bu lezyonun yaklaşık beş ay önce kendiliğinden ve küçük bir sertlik şeklinde oluşarak zamanla büyüklüğünün arttığını ve üç ay önce de üzerinde yumuşak kıvamlı kabarcık benzeri bir görünüm meydana geldiğini tanımlamıştır. Olgumuzun özgeçmişinden bu yakınmalarına herhangi bir semptomun eşlik etmediği ve lezyon bölgesine herhangi bir travma öyküsünün olmadığı belirlenmiştir.

Yazışma Adresi/Address for Correspondence: Dr. Sevgi Akarsu, Dokuz Eylül Üniversitesi Tıp Fakültesi, Deri ve Zührevi Hastalıkları Anabilim Dalı, İzmir, Türkiye Tel.: +90 2324123860 E-posta: sevgi.akarsu@deu.edu.tr Geliş Tarihi/Received: 11.05.2011 Kabul Tarihi/Accepted: 22.06.2011

Türkderm-Deri Hastalıkları ve Frengi Arșivi Dergisi, Galenos Yayınevi tarafindan basılmıștır.

Turkderm-Archives of the Turkish Dermatology and Venerology, published by Galenos Publishing. 
Ayrıca kendisinde veya ailesinde daha öncesinde benzer bir lezyon görülmediği tanımlanan olgumuzun soygeçmiş ve sistem sorgulamasında herhangi bir özellik belirlenmemiştir.

Olgumuzun dermatolojik muayenesinde sağ üst kolun yan yüzünde 2,2x1,6 cm boyutunda düzgün yüzeyli, ovoid yapılı, açık viyolase renkli, kalın duvarlı gevşek psödobüllöz görünümün altında palpasyonla yaklaşık 1,7x1,5 cm çaplı sert kıvamlı bir nodül izlenmiştir (Resim 1). Lenf nodu muayenesinde bölgesel lenfadenopati saptanmamıştır. Total olarak çıkarılan lezyonun histopatolojik incelemesinde PM ile uyumlu olarak hayalet ve bazaloid hücre adaları, yer yer multinükleer dev hücreler içeren granülasyon dokusu alanları ve dermiste yer yer genişlemiş lenfatik damarlar izlenmiştir (Resim 2a, b). Ayrıca izlenen ödemli alanların Alcian mavisi ile negatif boyanması miksoid görünüm olarak değerlendirilmiştir. Lezyonun üstündeki dermiste azalmış kollagen demetler ve elastik liflerin belirlendiği anetodermik değişiklikler ile uyumlu bulgular saptanmıştır (Resim 3a, b). Olgumuza bu klinik ve histopatolojik bulgular eşliğinde psödobüllöz anetodermik PM tanısı konulmuştur.

\section{Tartışma}

Illk kez 1880 yılında Malherbe ve Chenantais tarafından Malherbe'nin kalsifiye epitelyoması veya Malherbe tümörü olarak tanımlanmış olan PM, kıl folikülü matriks hücrelerinden köken alan derin dermal veya subkutanöz yerleşimli soliter bir deri tümörüdür1,2. Etyolojisi tam olarak bilinmemekle birlikte lezyonların oluşumunda travmanın rol oynayabileceği belirtilmiş, özellikle ailesel olan multipl ve tekrarlayıc PM'larda 3p22-p21,3 lokusundaki beta katenin gen mutasyonları saptanmıştır1,2,8. Hayatın ilk iki dekadı içinde en sık görülen benin adneksiyal tümör olmasına rağmen preoperatif doğru tanı oranlarının \%28,9 ile \%43 arasında değiştiği bildirilmiştir. Özellikle atipik lokalizasyonlu, değişik kıvamdaki ve üzerinde punktum benzeri görünümü olan kistik lezyonların görüldüğü ve klinik olarak kalsifikasyonun izlenmediği durumlarda epidermoid

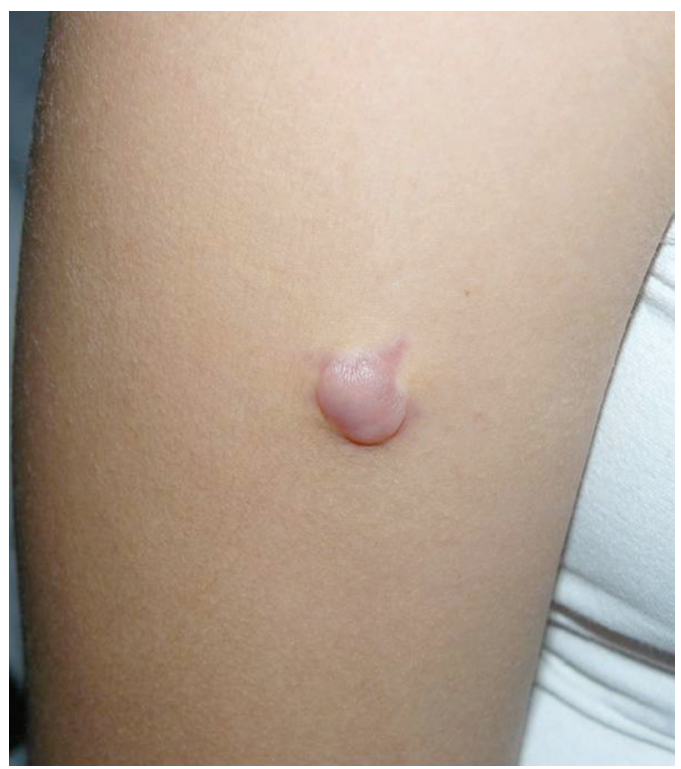

Resim 1. Sağ üst kolun yan yüzünde açık viyolase renkli, üzerinde kalın duvarlı gevşek bül benzeri görünümün izlendiği pilomatrikoma ile uyumlu sert kıvamlı nodül. veya dermoid kist, lipom, dermatofibrom, dejenere fibroksantom, steatokistoma simpleks, kalsifiye hematom, hemanjiom ya da lenf nodları, brakial yarık kalıntıları veya preaurikular sinuslar gibi diğer benin oluşumlar ile karışabilmektedir2,3. Klasik PM histopatolojisinde periferde çekirdekleri korunmuş bazaloid hücreler ve merkezde keratinizasyon sonucunda oluşan çekirdeksiz eozinofilik hayalet hücreler ile karakterize iyi organize olmuş hücre adalarından oluşan bağ dokusu kapsülüyle çevrilmiş iyi sınırlı bir tümör görülmektedir. Ayrıca bu bulgulara sıklıkla granülomatöz inflamasyon, yabancı cisim dev hücreleri ve distrofik kalsifikasyon da eşlik etmektedir2,4,5.

PM'lar içinde bizim olgumuzdakine benzer tarzda büllöz görüntüye neden olabilecek olan klinik formlar, nadir görülen büllöz ve anetodermik formlardır. Büllöz PM'da altta palpe edilebilen sert tümörün üzerinde kalın duvarlı gevşek bül benzeri bir görünüm izlenmektedir. Histopatolojisinde derin dermisteki tipik PM özelliklerini gösteren tümörün üzerinde Alcian mavisi ile negatif boyanan miksoid görünümlü dermal ödem, çok sayıda küçük kan damarları ve kronik
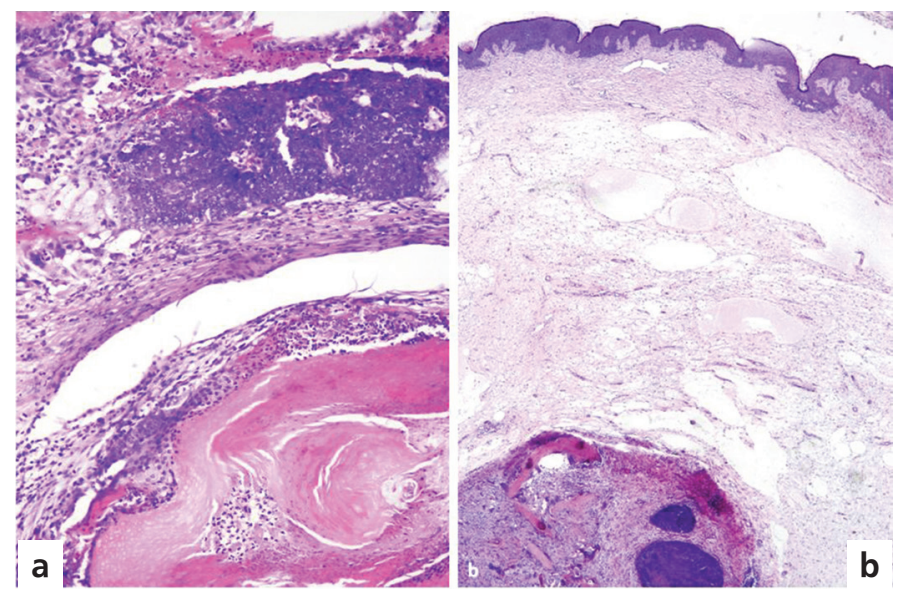

Resim 2. a) Tipik pilomatrikoma morfolojisi ile uyumlu en altta hayalet hücre tabakası, daha üstte bazaloid hücre proliferasyonu ve çevrede yabancı cisim reaksiyonu (HE x20); b) Lezyon üzerindeki alanda genişlemiş lenfatik damarlar (HE X4).

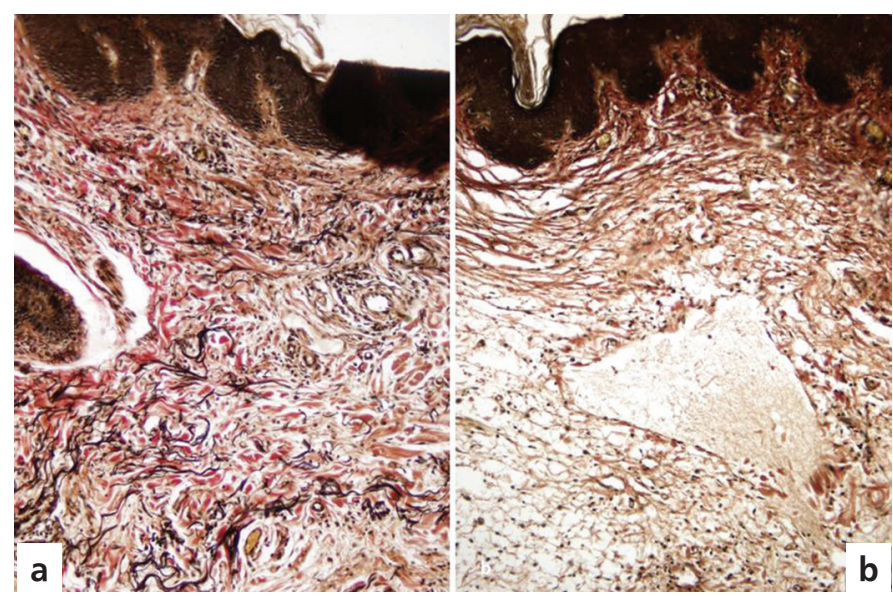

Resim 3. a) Elastik doku boyamasıyla lezyon çevresindeki deride elastik liflerin normal görünümü (Verhoeff-van Gieson X20); b) Lezyonun üstündeki dermiste elastik liflerin azalmış görünümü (Verhoeff-van Gieson X20). 
inflamatuvar hücre infiltrasyonu ile ilişkili genişlemiş lenfatik damarlar görülmektedir1,6-12. Illk kez 1943 yılında tanımlanan ve tüm PM'lı olguların \%2'sini oluşturan anetodermik form ise klinik olarak gevşek, sarkık veya kese benzeri bir lezyon şeklinde görülebileceği gibi, keloid veya hipertrofik sikatris benzeri ya da buruşuk ve oldukça katlantılı atrofik deriyle örtülü psödobüllöz görünümlü bir lezyon şeklinde de karşımıza çıkabilir. Anetodermik PM formunun histopatolojisinde lenfatik dilatasyon ve dermal ödem yanında anetodermik değişiklikler ile uyumlu olarak elastik liflerde azalma ve kollajen liflerde güçsüzleşme belirlendiği bildirilmiştir13-17. Bazı yazarlar tarafından büllöz görünüme yol açan bu iki klinik formun psödobüllöz veya lenfanjiektatik form olarak adlandırılan benzer antiteler olduğu ileri sürülmekle birlikte, büllöz PM'da histopatolojik olarak gerçek bir dermal bülün görülmesi ile PM'nın anetodermik değişiklik gösteren formundan ayırt edilebilmesinin mümkün olabileceği ileri sürülmüştür. Büllöz görünümlü $P M^{\prime}$ 'sı olan olguların ayırıcı tanısında ayrıca büllöz morfea, penisilamine sekonder gelişen dermal büllöz lezyonlar, lenfanjiom ve kutanöz lenfoma da düşünülmelidir11,12. Bizim olgumuzda histopatolojik olarak anetodermik değişikliklerin izlenmesi ancak gerçek bir dermal bül formasyonunun izlenmemesi, klinik olarak izlenen kalın duvarlı gevşek psödobüllöz görünümün anetodermik PM formu ile uyumlu olduğunu düşündürmektedir. PM'lı olgularda büllöz görünümün oluşum mekanizması tam olarak bilinmemekle birlikte temel olarak PM sert yapısının neden olduğu lenfatik obstrüksiyonun primer rol oynadığı düşünülmektedir. Bunun sonucunda oluşan lenfatik sIVı konjesyonu, lenfatik damarlarda dilatasyon, lenfatik sızıntı ve tümörü çevreleyen dermisteki ödem büllöz görüntüye neden olmaktadır7-9. Bununla birlikte literatürde mekanik irritasyon ve köpek tırmalaması ile ilişkili nadir olgu bildirileri de mevcuttur9,11,12. Diğer bir teori ise özellikle mekanik irritasyon varlığında tümör hücreleri ve/veya inflamatuvar infiltrasyondaki hücrelerin elastolitik inflamatuvar enzimler üreterek kollajen ve elastik doku kaybı ile lenf damarlarında destrüksiyon ve dilatasyon oluşumuna yol açtığı şeklindedir8,15. Bu nedenle tipik PM'ların baş ve boyunda lokalize olmasına karşın, anetodermik formun devamlı basınç veya mekanik irritasyona maruz kalınmasının etkisiyle bizim olgumuzda olduğu gibi ekstremite, omuzlar veya gövdede yerleştiği bildirilmiştir ${ }^{15}$.

Sonuç olarak, bizim olgumuzda histopatolojik olarak çok sayıda genişlemiş lenfatik ve kan damarlarının görülmesi yanında anetodermik değişikliklerin de belirlenmesi PM'larda büllöz görünümün oluşumunda lenfanjiektatik ve anetodermik değişikliklerin rolünü desteklemektedir.

\section{Kaynaklar}

1. Julian CG, Bowers PW: A clinical review of 209 pilomatricomas. J Am Acad Dermatol 1998;39:191-5.

2. Pirouzmanesh A, Reinisch JF, Gonzalez-Gomez I, Smith EM, Meara JG: Pilomatrixoma: a review of 346 cases. Plast Reconstr Surg 2003;112:1784-9.

3. Kumaran N, Azmy A, Carachi R et al: Pilomatrixoma-accuracy of clinical diagnosis. J Pediatr Surg 2006;41:1755-8.

4. Cankorkmaz L, Özer H, Altuntaş EE, et al: Clinicopathologic analysis of childhood pilomatricoma cases. Turkiye Klinikleri J Pediatr 2009;18:76-81.

5. Mansur AT, Serdar ZA, Erçin Z, Gündüz S, Aker F: The clinical and histopathologic features of 25 pilomatricoma cases. Türkderm 2004;38:37-40.

6. Prasad HR, Verma KK, Khaitan BK, Singh MK: Bullous pilomatricoma: a rare occurrence. Acta Derm Venereol 2001;81:217-8.

7. Fetil E, Soyal MC, Menderes A et al: Bullous appearance of pilomatricoma. Dermatol Surg 2003;29:1066-7.

8. Yiqun J, Jianfang S: Pilomatricoma with a bullous appearance. J Cutan Pathol 2004;31:558-60.

9. Inui S, Kanda R, Hata S: Pilomatricoma with a bullous appearance. J Dermatol 1997;24:57-9.

10. Karadağ AS, Ekşioğlu M, Özlük E, et al: A Rare Case of Pilomatricoma with Bullous Appearance. Turk J Med Sci 2009;39:333-6.

11. de Giorgi V, Alfaioli B, Massi D et al: Bullous pilomatricoma: a particular and rare dermal bullous disorder. Acta Derm Venereol 2009;89:189-90.

12. Weichert GE, Bush KL, Crawford RI: Bullous pilomatricoma: a report of clinical and pathologic findings and review of dermal bullous disorders. J Cutan Med Surg 2001;5:394-6.

13. Jones CC, Tschen JA: Anetodermic cutaneous changes overlying pilomatricomas. J Am Acad Dermatol 1991;25:1072-6.

14. Shames BS, Nassif A, Bailey CS, Saltzstein SL: Secondary anetoderma involving a pilomatricoma. Am J Dermatopathol 1994;16:557-60.

15. Fujioka M, Gozo N, Osamu M, Tsuneyuki Y, Takehisa Y: Secondary anetoderma overlying pilomatrixomas. Dermatology 2003;207:316-8.

16. Fernandes BF, Al-Hinai A, Belfort RN, et al: Anetodermic variant of a periorbital pilomatricoma. Ophthal Plast Reconstr Surg 2008;24:419-21.

17. Fernández-Flores A, Gonzalez-Montero JM: Anetodermic variant of pilomatricoma. Int J Dermatol 2005;44:876-7. 